"Mircea cel Batran" Naval Academy Scientific Bulletin, Volume XX - 2017 - Issue 1

The journal is indexed in: PROQUEST / DOAJ / Crossref / EBSCOhost / INDEX COPERNICUS / DRJI / OAJI I

JOURNAL INDEX I I2OR / SCIENCE LIBRARY INDEX / Google Scholar / Academic Keys/ ROAD Open Access I Academic Resources / Scientific Indexing Services / SCIPIO I JIFACTOR

\title{
THE INTERACTIONS BETWEEN DRAWING PROCESSING ELEMENTS AND THEIR INFLUENCE ON THE QUALITY PARTS
}

\author{
Aurelia CHIOIBAS ${ }^{1}$ \\ ${ }^{1}$ Lecturer Ph. D. Eng Dep. IMAN, Naval Academy "Mircea cel Batran", Str. Fulgerului nr. 1, \\ chioibasaura@yahoo.com
}

Abstract: In this paper is present the influences between the components of technological drawing system and elements that make up the process drawing, which is reflected in the quality of parts obtained.

Key words: drawing process, drawing technological system, quality of drawing part

Between the drawing technological system components and the elements that make up the process drawing [2] exist influences that determine the quality of parts obtained and that make the scope of this paper.

1. Influence of the subsystem "Blank" on the drawing process and quality drawing parts

Material influences the following
components: strength $\sigma_{r}$ [4]. The drawing force for $g<d$, is determined by the relationship:

$$
\mathrm{F}_{\mathrm{a}}=\pi \cdot \mathrm{d} \cdot \mathrm{g} \cdot \sigma_{\mathrm{a}}
$$

where $d$ is the diameter of the workpiece, $g$ is the thickness of the material, $\sigma_{a}$ the tension in the drawing and iscalculatedwithequation (2 [7]).

$$
\sigma_{\mathrm{a}}=\left[11 \sigma_{\mathrm{c}} \ln \frac{\mathrm{R}}{\mathrm{r}}+\mu \mathrm{q} \frac{\mathrm{D}^{2}-\left(\mathrm{d}+\mathrm{g}+2 r_{\mathrm{pl}}\right)^{2}}{2 \mathrm{gd}}\right](1+1,6 \mu)+\frac{\sigma_{\mathrm{c}}}{2 \frac{r_{\mathrm{pl}}}{\mathrm{g}}+1}
$$

The sizes of the equation (2) have the following meaning: $R$ - the blank radius, $r$ - the piece radius, $D=2 R, d=2 r, r_{p l}$ - radius drawing board [2]; $q$ is the pressure retaining applied to blank through the retaining ring, $\mu$ is the coefficient of friction between the blankand the boardactive, $\sigma_{c}$ is the yield strength of the material.

- hardening, which increases as greater elongation;

- drawing tension from the value $\sigma_{c}$. With the increase of carbon content in steel increases the mechanical strength characteristics, and reduces the plasticity. Also alloying elements in the composition of steels are provided within certain limits because they decrease their plasticity.

- the homogeneity, otherwise the deformations are not uniform;

$\Delta d$ elastic recovery because it increases with decreasing plasticity (Fig.1 [5]).

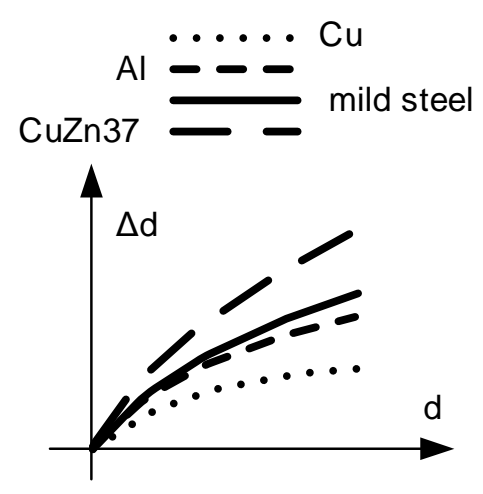

Fig. 1. The spring action variation depending on the diameter for various degrees of plasticity of sheet material

Delivery status of the material (annealed or hardened) influences the following components:

- the force deformation, by $\sigma_{\mathrm{r}}$ yield point of the material;

- the elastic recovery by the features plasticity;

- the dimensional accuracy, because a hardened material has a more pronounced springback;

- the surface smoothness, because the possible non-metallic inclusions or using a semikilled steel would give rise fissures, superficial cracks or improper appearance. To obtain the appearance, the sheets were subjected to a cold rolling process on special rolling mill fitted with several cylinders, providing thickness reduction of 2\%).

Metallographic structure influences the following components:

- the surface smoothness by grain size;

- the drawing tension from the value of the yield strength, conferred by metallographic constituents; 
"Mircea cel Batran" Naval Academy Scientific Bulletin, Volume XX - 2017 - Issue 1

The journal is indexed in: PROQUEST / DOAJ / Crossref / EBSCOhost / INDEX COPERNICUS / DRJI / OAJI I JOURNAL INDEX / I2OR / SCIENCE LIBRARY INDEX / Google Scholar / Academic Keys/ ROAD Open Access I Academic Resources / Scientific Indexing Services / SCIPIO I JIFACTOR

- the springback and the deformation force, by the type of constituents (the pearlite hardness greater than the hardness of ferrite) and the fineness of the structure (a fine structure leads to a greater resistance to deformation). The structures that gives the best behavior to deformation are ferrite or ferrite-pearlite uniform structures.

The anisotropy influences dimensional and precision accuracy of shape by forming the festoons (Fig. 2 [3], Fig. 3 [6]).

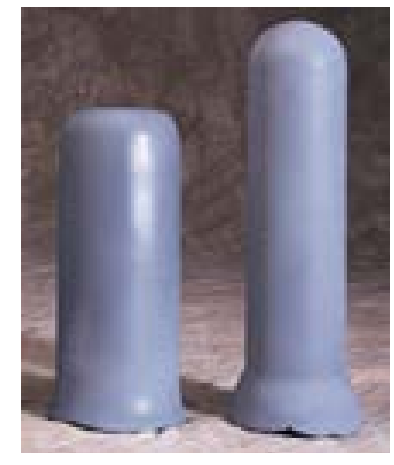

Fig. 2. Festoons occurrence is determined by anisotropy

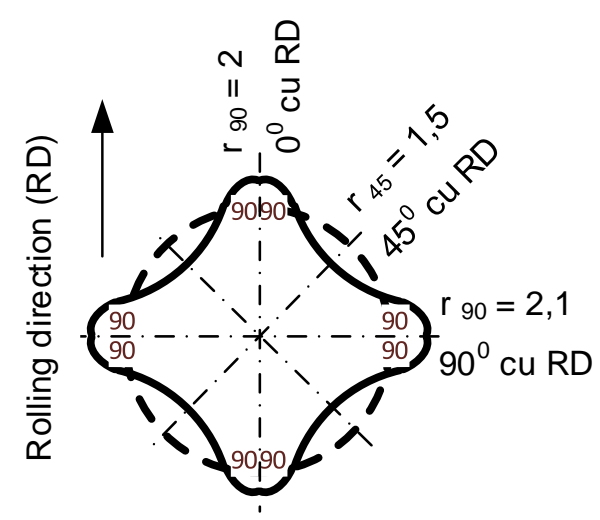

Fig. 3. The variation of anisotropy coefficient with rolling direction which

leads to the formation of festoons

The shape of the blank influences:

- tensions; for drawing a small cylindrical parts are obtained tensions different from a cylinder piece large or a car body;

- the shape partaccuracy, through correct cutting of the blank [2].

The blank dimensions influences:

- the dimensional accuracy of the piece (dimensional accuracy of the blank leads to a dimensionally accurate parts);

- the springback because it increases for small thicknesses (Fig. 4 [5], $\Delta \mathrm{d}_{\mathrm{i}}$ - the springback

(c) 2017. This work is licensed under the Creative Commons Attribution-Noncommercial-Share Alike 4.0 License. at the bottom; $\Delta \mathrm{d}_{\mathrm{s}}$ - the springback at the top; $\mathrm{d}$ workpiece diameter); it is observed that regardless of the material thickness, the springback increases with increasing the piece diameter.

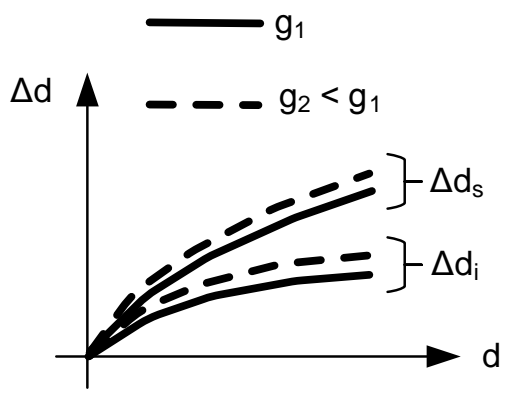

Fig. 4. The spring action variation depending on the diameter for different sheet thickness

- the radial stresses which depend on the thickness and the plane blank radius $R$ (3 [1], $r$ is the workpiece radius);

$$
\sigma_{\rho}=\sigma_{c} \cdot \ln \frac{R}{r}
$$

- the deformation force which depends on the tensions;

- the degree of deformation which increases with the relative thickness of the blank $[(g / D) \cdot 100]$.

Type of blank (individual or band) influences the tensions, which determines the state of deformation.

2. Influence of the subsystem "Die" on the drawing process and drawn parts quality

The active plate shape [2] characterized by too high of $r_{p l}$ can determine the wrinkles in blank flange or the material thinning in the dangerous section, so that influenced the dimensional accuracy, the shape accuracy and the surface roughness. The dimensional accuracy of the die, implicitly its wear, influences precision outer dimensions of the piece. $r_{p l}$ value influence the type retaining blank, that has an impact on piece quality. Thus, in the case of high values thereof and the choice of a retention plane [2], the material coming out from under the retaining ring can wrinkle on the toroidal plate so that it can cause breakage at the entry into the clearance between the punch and the plate.Choice of large 
"Mircea cel Batran" Naval Academy Scientific Bulletin, Volume XX - 2017 - Issue 1

The journal is indexed in: PROQUEST / DOAJ / Crossref / EBSCOhost / INDEX COPERNICUS / DRJI / OAJI I

JOURNAL INDEX / I2OR / SCIENCE LIBRARY INDEX / Google Scholar / Academic Keys / ROAD Open Access I Academic Resources / Scientific Indexing Services / SCIPIO I JIFACTOR

values of radius is permitted when using combined retention.

A punch tapered [2] characterized $r_{1}>r_{p}$ where $r_{p}$ is the radius of a cylindrical punch (used in small parts drawing), leads to a better quality parts. $r_{p}$ high, the deformation is achieved more easily and as a result the degree of deformation may have high values, so that the latter determines the occurrence of large deformations. The dimensions that characterize the punch shape influence the internal dimensions accuracy of the parts.

The clearance of active elements influences:

- $\quad$ the shape accuracy, because if it $j>g$ the diameter to top of part is higher than the bottom (Fig. 5[7]); Drawing parts without willful changing of the wall thickness result with small deviations from cylinder shape for the case $\mathrm{j}=\mathrm{g}$; cylindrical shape of the piece is preserved best in the drawing case with thinning. achieved on account of the active plate adjustment; how the punch wear is negligible, the change of the clearance will be influenced by the active plate wear..

- the surface smoothness is good if $\mathrm{j} \leq \mathrm{g} ; \mathrm{A}$ good smoothness of active elements surface influencing positively on piece and allows an increase of degree of deformation.Possible impurities of existing on the surface cause of scratches drawing board, that the piece roughness worsens.

- the springback, which increases with the clearance (Fig. 5)

3. Influence of the subsystem "Presser" on the drawing process and drawn parts quality

The presses influences the drawing process through speed of the ram, which can be constant for the hydraulic and variable for the mechanical [8].

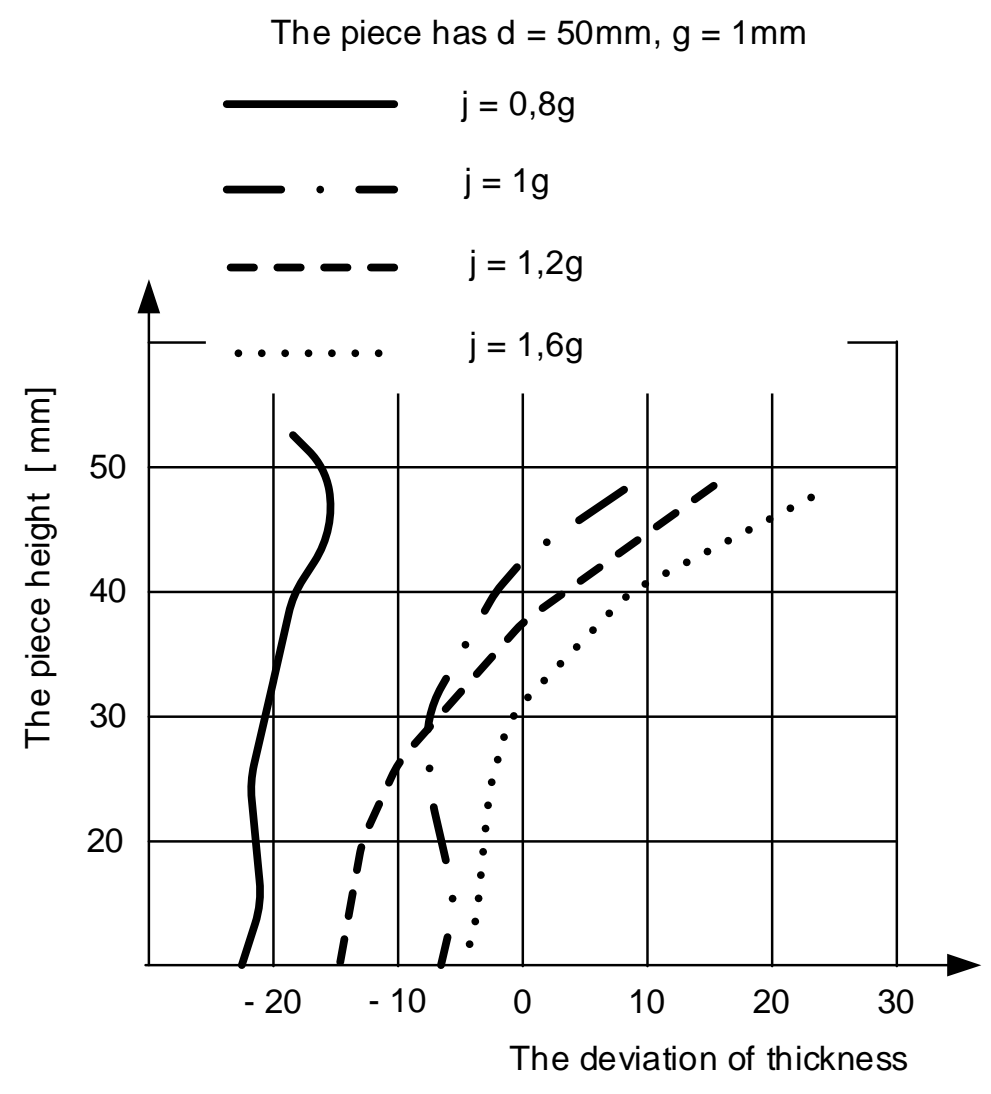

- the

Fig. 5. The variation of deviations thickness along piece height

dimensional accuracy, so that when the external dimension of the piece is the main, $j$ is made on account the punch adjustment;in the case of obtaining the accurate size of the interior, $j$ is 


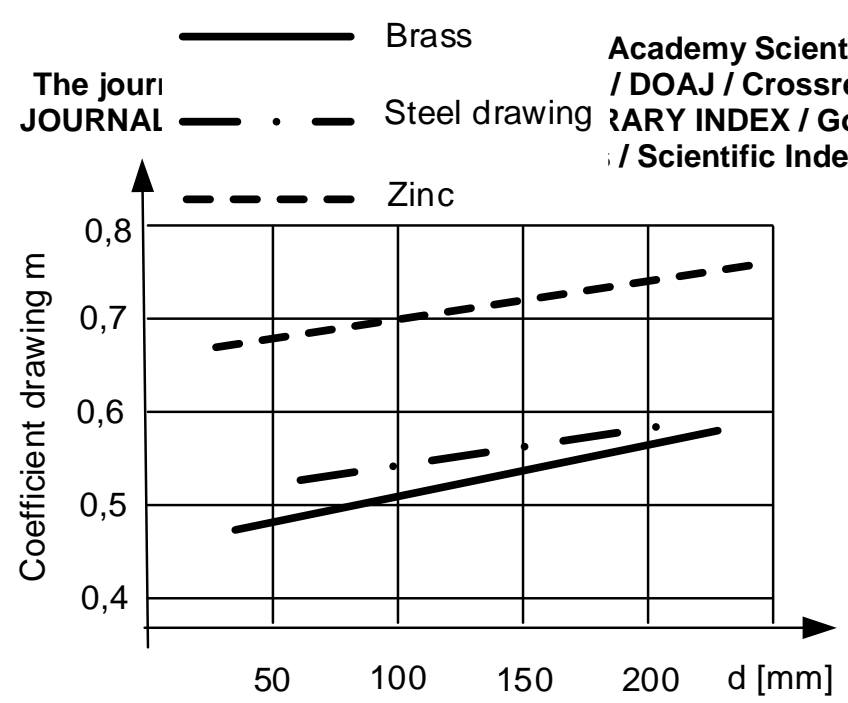

Fig. 6. The variation drawing coefficient depending on the matrial plasticity



Fig. 7a. The spring action of cylindrical part with flange along its height

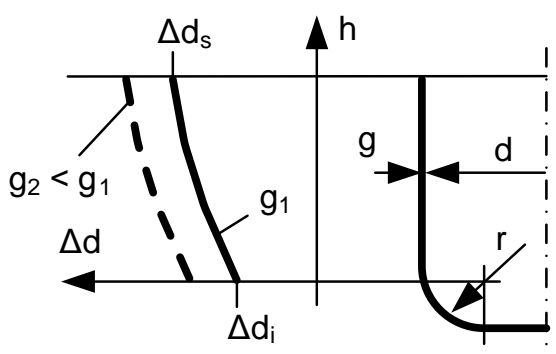

Fig. 7b. The spring action of cylindrical part without flange along its height

\section{Influence of "Drawing process" on the} drawn parts quality

\subsection{Influence of factor "Piece"}

The piece shape influences:

- the accuracy of its shape that should correspond to imposed deviations shape;

- $\quad$ the degree of deformation $(\mathrm{K})$, since each type of configuration corresponds to other values. The degree of deformation is the inverse of the drawing coefficient $(\mathrm{m})$. In Figure 6 presents the variation depending on the plasticity of materials and observe that it has the lowest values for brass, which has the best plasticity.

- the tensions, which differs from cylindrical piece at a car body;

- the springback, which is the maximum at (0.3 ... 0.4)h from the base for the piece with wide flange and in the case of parts with narrow flange or without flange is maximum at the top (Fig. 7 [5]).

Size of the piece influence:

- the dimensional accuracy, which must be located in field of tolerance provided;

- the degree of deformation, because at small size of the pieces can adopt values of " $\mathrm{m}$ " smaller than in the case of large pieces (Fig.6). This degree of deformation is related to the degree of hardening of the material, so that the relationship is valid below between coefficients drawing on operations:

$m_{1}<m_{2}<\ldots<m_{n}, m_{1}=d_{1} / D, \ldots, m_{n}=d_{n} / d_{n-1}$.

(4)

Practically it is considered $m_{2}=m_{3}=\ldots=m_{n}$.

- the relative thickness influences the drawing coefficient values, in the sense that it decreases with increasing thickness in the case of cylindrical parts with flange;

- $\quad$ the speed of the ram; in case of using the crank press (eccentric), it depends on the height of the piece and the length of the stroke of the press; in the case determining of the beginning of its working stroke, it depends on the difference (D - d).

\subsection{Influence of factor „Friction”}

The nature of the lubricant (liquid or solid) and its right choice, depending on the nature of the material, influences the smoothness of the surface, the tension values, which in turn determines the degree of hardening of the material. The lubricants cause decrease of 2 to 3 times the coefficient of friction. For the avoidance slipping blank under the punch, the lubricant is preferable to apply on active plate and on retaining ring and the punch cleaning at certain intervals time. The active plate stepwise allow the better retention of the lubricant ([2], [5]).

\subsection{Influence of factor „Force”}

The deformation force influence: 
"Mircea cel Batran" Naval Academy Scientific Bulletin, Volume XX - 2017 - Issue 1

The journal is indexed in: PROQUEST / DOAJ / Crossref / EBSCOhost / INDEX COPERNICUS / DRJI / OAJI I JOURNAL INDEX I I2OR / SCIENCE LIBRARY INDEX / Google Scholar / Academic Keys/ ROAD Open Access I Academic Resources / Scientific Indexing Services / SCIPIO / JIFACTOR

- $\quad$ the friction force size;

- the dimensional accuracy, meaning that for $\mathrm{F}_{\mathrm{a}}<\mathrm{F}_{\text {opt }}$ can not get appropriate size;

The pressure retaining $(q)$ determines the dimensional and shape accuracy of the part because the value $\mathrm{q}<\mathrm{q}_{\text {opt }}$ is possible to lift
The tensions influence:

- value $\mathrm{F}_{\mathrm{a}}(1)$;

- the degree of hardening, because the tensions values determines the increase of resistance to further deformation; state of deformation, which is shown in Fig. 8 [1].

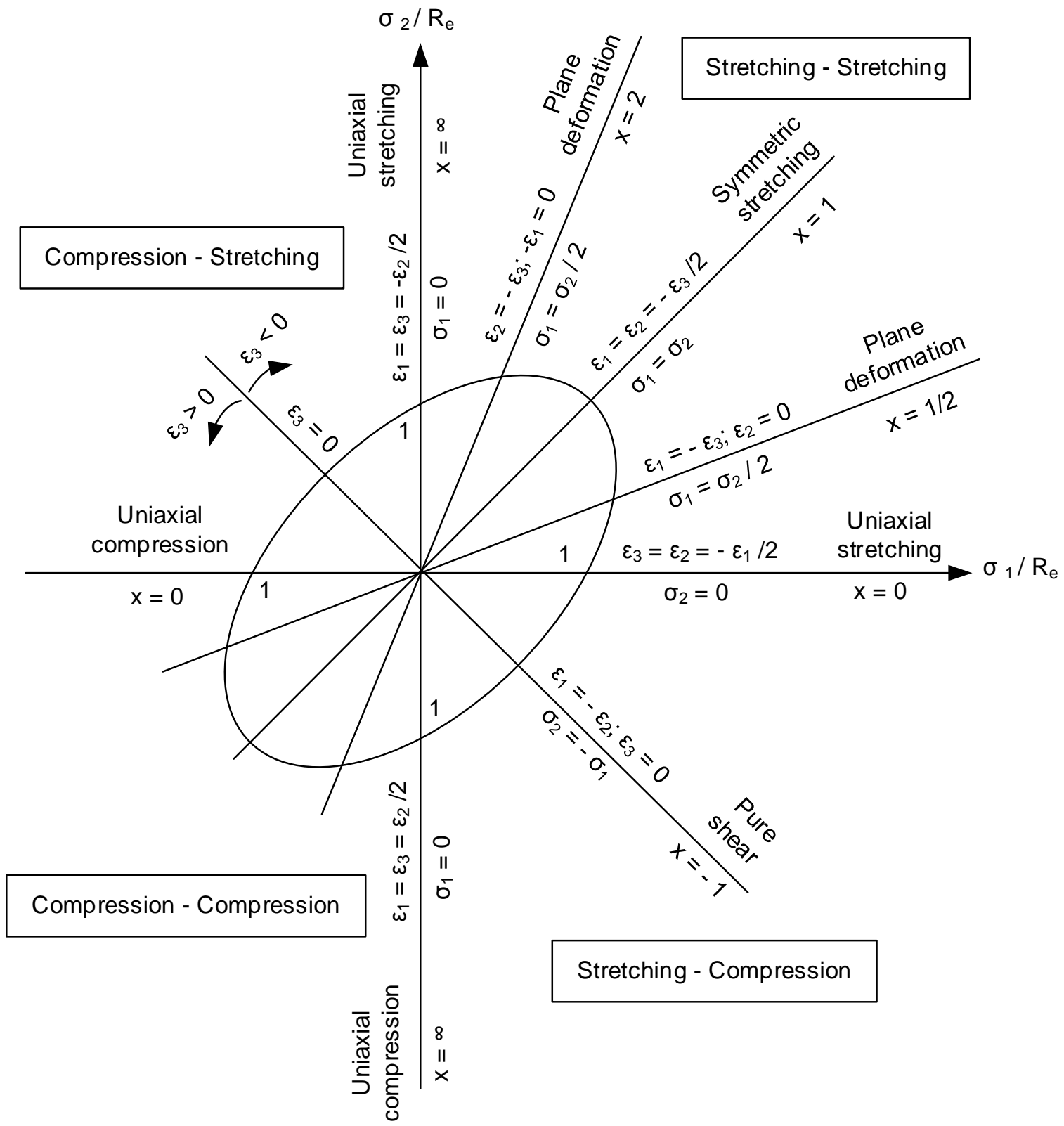

Fig. 8. Deformations and stresses state In the case deformation plate retaining ring which would lead to wrinkles.

\subsection{Influence of factor „Tension”}


"Mircea cel Batran" Naval Academy Scientific Bulletin, Volume XX - 2017 - Issue 1

The journal is indexed in: PROQUEST / DOAJ / Crossref / EBSCOhost / INDEX COPERNICUS / DRJI / OAJI I JOURNAL INDEX / I2OR / SCIENCE LIBRARY INDEX / Google Scholar / Academic Keys/ ROAD Open Access I Academic Resources / Scientific Indexing Services / SCIPIO / JIFACTOR

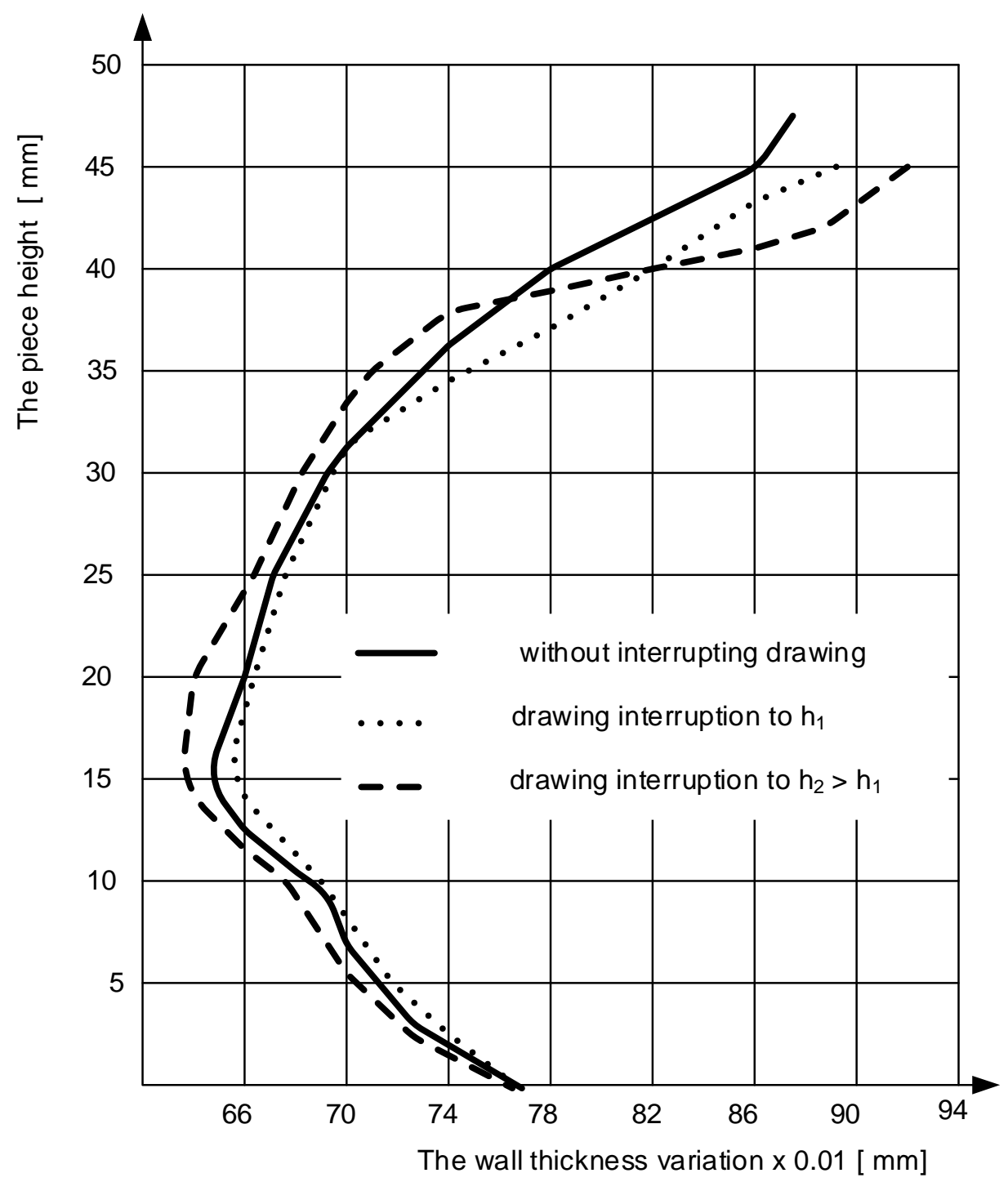

Fig. 9. The wall thickness variation in height along the piece

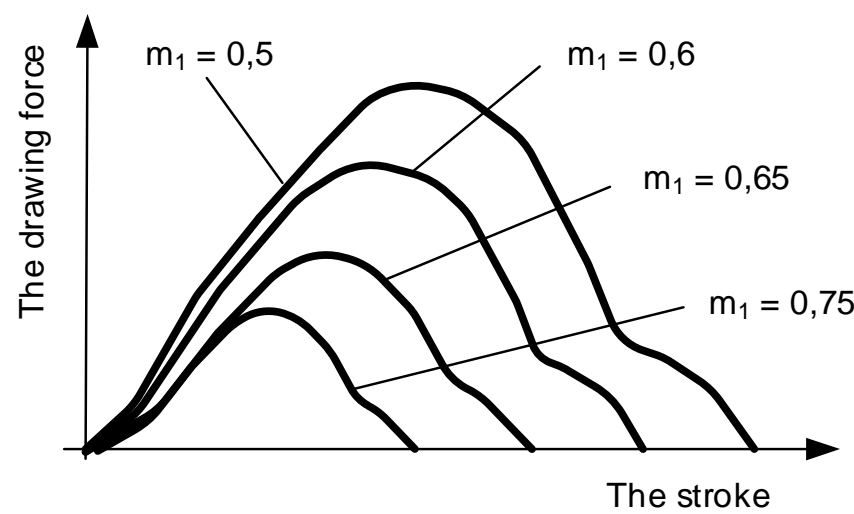

Fig. 10. The drawing force variation depending on the punch stroke for different degrees of deformation $\mathrm{m}_{1}$ (first drawing) 


\begin{abstract}
"Mircea cel Batran" Naval Academy Scientific Bulletin, Volume XX - 2017 - Issue 1
The journal is indexed in: PROQUEST / DOAJ / Crossref / EBSCOhost / INDEX COPERNICUS / DRJI / OAJI I JOURNAL INDEX I I2OR / SCIENCE LIBRARY INDEX / Google Scholar / Academic Keys/ ROAD Open Access I Academic Resources / Scientific Indexing Services / SCIPIO / JIFACTOR
\end{abstract}

4.5. Influence of factor „Displacement”

In the case no thinning drawing part, achieved without interruption of the process or the interruption at different heights, the part suffers slight deviations from cylindricity and respectively on the height of the wall thickness (Fig. 9 [3]). It can be seen that the appearance of the curves is similar to that of Fig. 5 , for $j=g$. This confirms influence on the shape and dimensions accuracy of piece pressed made of punch displacement.

\subsection{Influence of factor "The speed"}

The deformation speed influence:

- the surface smoothness, in the sense that the optimal value, correlated with the use of a corresponding lubricant, is obtained a good quality;

- for small values allows working with large degrees of deformation, which increases the degree of hardening.

\subsection{Influence of factor „Degrees of} deformation"

Degrees of deformation influence:

- strains and stresses values (which depend on size);

- the force deformation values; in Figure 10 [6]) is shown as a drawing force decreases to decrease of the deformation degree (respectively to increase the drawing coefficient). Also, increase the degree hardening determine the increase of degree deformation and implicit of $F_{a}$ to further processing.

- the choice of lubricant used.

\section{The quality characteristics of drawing} parts

The drawing parts quality refers to the quality of their manufacturing. It is characterized by the function of physical continuity of the piece, the dimensional accuracy, the shape accuracy, the relative position accuracy of surfaces, the surfaces piece smooth as well as physical, chemical and mechanical properties of the workpiece material, corresponding to development of the functions necessary to satisfy a given need.

The manufacturing quality of drawing parts is the result of interactions between the technological system components and the processing by cold plastic deformation (Fig. 11).
The analysis of factors that influencing the quality characteristics of drawing parts is given in Fig. 12.

The dimensional, shape and relative position of the surfaces accuracy of the pressed parts is defined by the closeness of the effective size, shape and relative position of the parts pressed compared to the ones prescribed by their drawings.

Dimensional accuracy is influenced by both the dimensional accuracy of the elements of the drawing die and the accuracy of the relative position of these elements in the mold assembly. The die durability and wear parts working of the active elements influence the dimensional accuracy. The more is higher durability, wear allowed is higher and the dimensional accuracy of drawing parts is less. The accuracy of blank thickness also influences the accuracy of the piece. It is therefore recommended the use of the blanks with high precision of the thickness, corresponding of the class C, according to STAS. The precision cutting to dimension of the individual blanks influence the dimensional accuracy of the piece. The clearance between the active plate and punch, the size and uniformity of its arrangement influence the dimensional accuracy drawing parts. The clearance smaller ensures higher accuracy. The dimensional accuracy of the workpiece is influenced by the number of successive operations in which this is achieved. The greater the number of these operations, the the dimensional accuracy and the relative position of surfaces pieces will decrease. The calibration operation increases the accuracy drawn part. The springback reduce the dimensional accuracy and the shape accuracy. The positioning accuracy of the blank in the die and maintain it during drawing influence the workpiece accuracy. Also, friction between the punch and blank influence the dimensional accuracy. The anisotropy of blank material and its delivery status influence the dimensional accuracy. The isotropy is better and blank material has a higher plasticity and both the dimensional accuracy is better. Size pressing retaining and uniformity of its application on the blank flange influence precision drawing parts. The optimal holding pressing ensure obtaining of parts with maximum precision. The accuracy 
"Mircea cel Batran" Naval Academy Scientific Bulletin, Volume XX - 2017 - Issue 1

The journal is indexed in: PROQUEST / DOAJ / Crossref / EBSCOhost / INDEX COPERNICUS / DRJI / OAJI I

JOURNAL INDEX / I2OR / SCIENCE LIBRARY INDEX / Google Scholar / Academic Keys/ ROAD Open Access I Academic Resources / Scientific Indexing Services / SCIPIO I JIFACTOR

stroke of press influence the height precision of drawing parts.

The accuracy of the die shape and in particular shape of the punch is copied in processing, so that the accuracy of shape surfaces workpiece is influenced. The sprigback strongly influences the accuracy of surfaces shape the workpiece, which is higher at pieces without flange than the pieces with the flange. For its part, the springback is influenced by the ratio between the elastic and plastic deformations which occur in the material of the workpiece during drawing. The rigidity of the part contributes to reducing the influence of the springback. The anisotropy of the material determines the deviations of the workpiece shape of both the longitudinal and cross-section. The size of the retaining pressing, the uniformity of its application on the flange blank and maintain it for the duration of processing influence the shape piece accuracy. A retaining pressure less than the optimal retaining leads to undulations in the blank flange which give rise to wrinkles in the wall of the workpiece.
The termination of pressing retaining action before the end of the drawing also leads to wrinkles at the edge of the part to be obtained.

Ensuring the plastic deformation uniformity along the outline part to be obtained, especially pieces of square or rectangular box shape reduces the shape deviations of surfaces piece. Residual stresses in the material drawing piece influences strongly the shape accuracy of these parts.

The relative position surfaces accuracy is influenced by the number of successive drawing operations, especially in the case of parts with complex shapes. The existence of calibration operations improves the accuracy of the relative position of the surfaces. In the case of successive drawing of the tape, the relative position of the active elements accuracy influence the relative position surfaces accuracy of part to be obtained, and the positioning accuracy of the tape in the die for each successive drawing of the piece is obtained.

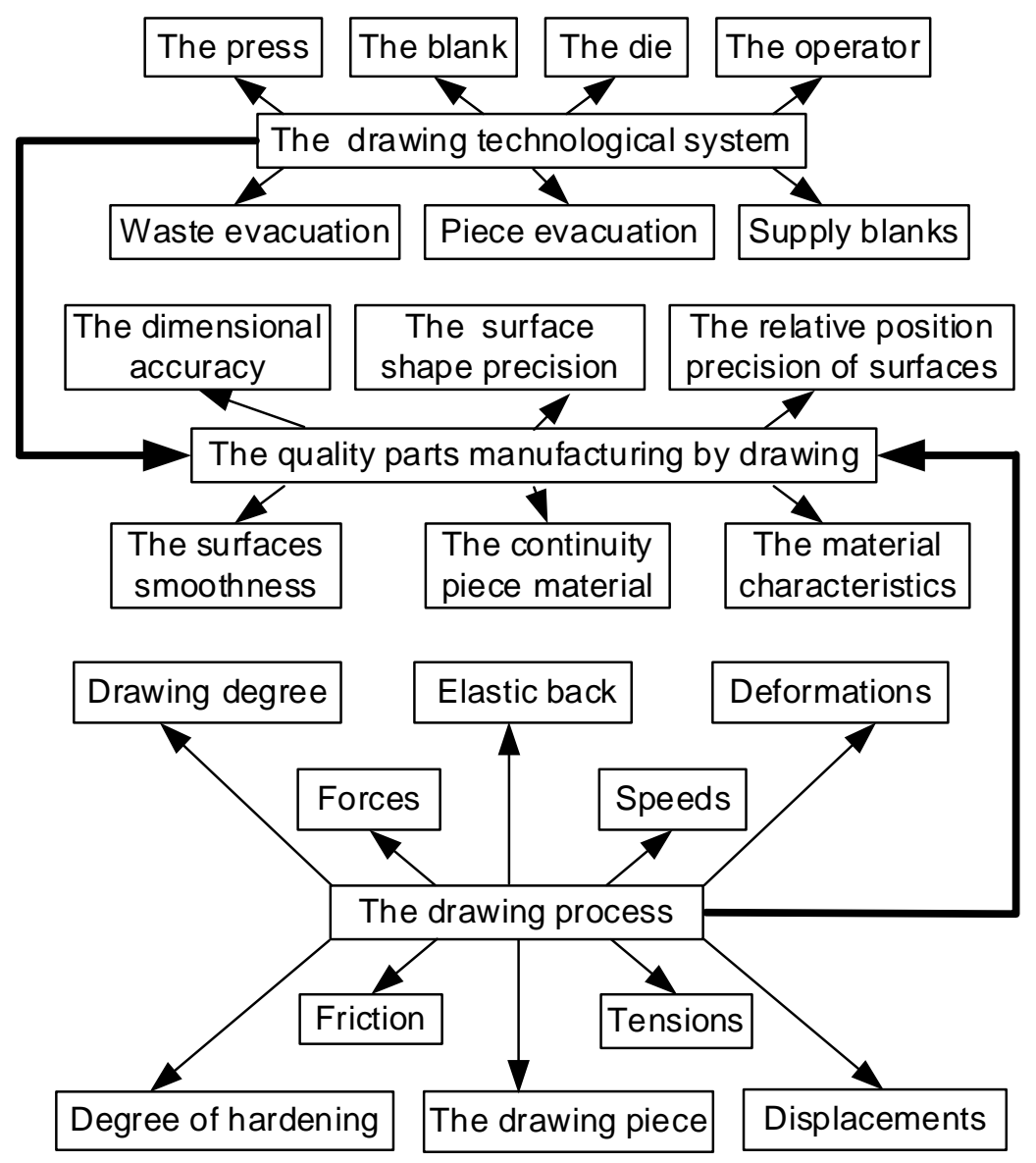

Fig. 11. Influence of the technological system and the drawing process on the quâiky of the drawn workpiece 
"Mircea cel Batran" Naval Academy Scientific Bulletin, Volume XX - 2017 - Issue 1

The journal is indexed in: PROQUEST / DOAJ / Crossref / EBSCOhost / INDEX COPERNICUS / DRJI / OAJI I JOURNAL INDEX I I2OR / SCIENCE LIBRARY INDEX / Google Scholar / Academic Keys/ ROAD Open Access I Academic Resources / Scientific Indexing Services / SCIPIO / JIFACTOR

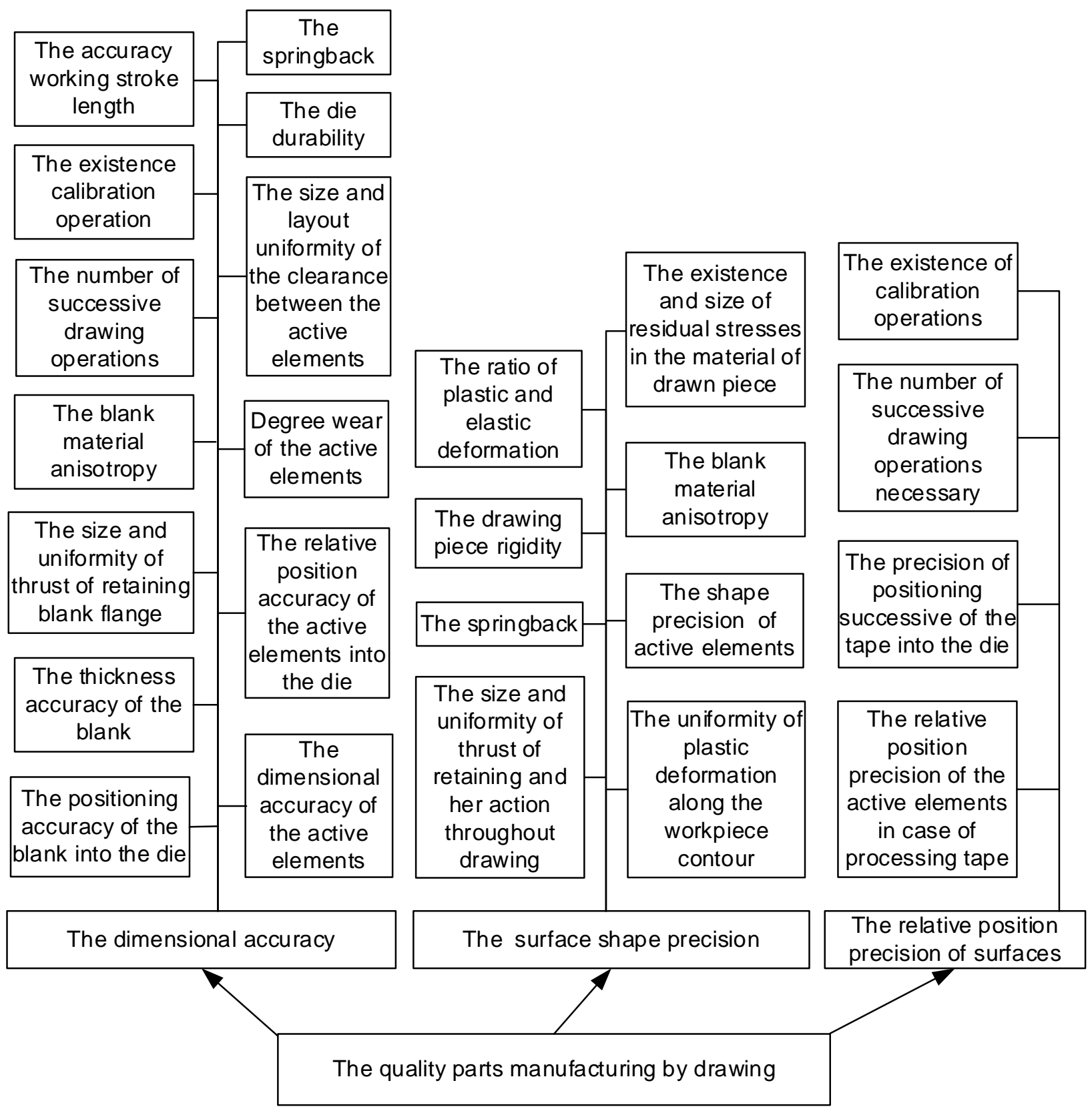

Fig. 12a. The features of quality drawing parts and the factors that influence them 
"Mircea cel Batran" Naval Academy Scientific Bulletin, Volume XX - 2017 - Issue 1 The journal is indexed in: PROQUEST / DOAJ / Crossref / EBSCOhost / INDEX COPERNICUS I DRJI / OAJI / JOURNAL INDEX I I2OR / SCIENCE LIBRARY INDEX / Google Scholar / Academic Keys/ ROAD Open Access I Academic Resources / Scientific Indexing Services / SCIPIO / JIFACTOR

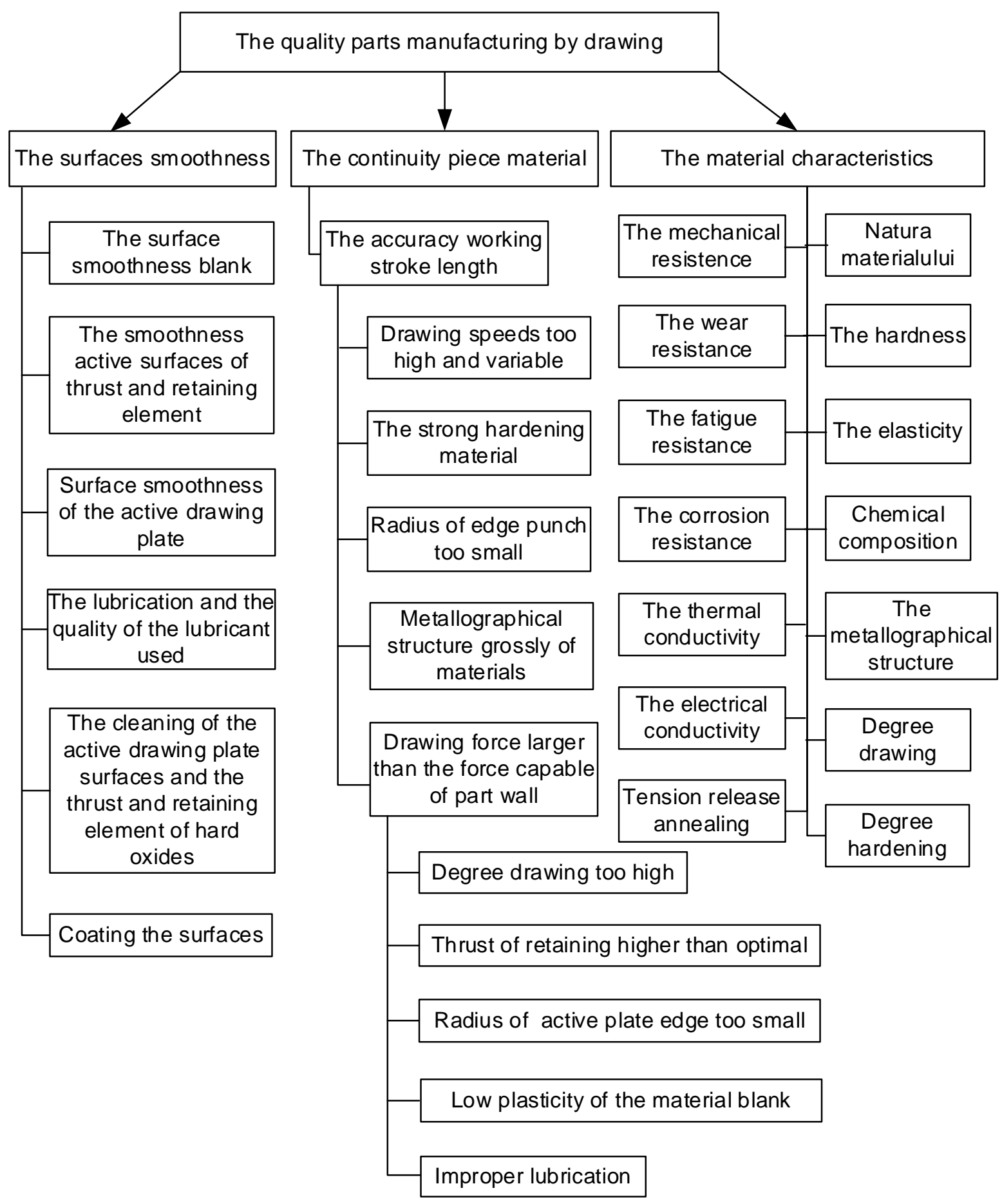

Fig. 12b. The features of quality drawing parts and the factors that influence them 


\section{"Mircea cel Batran" Naval Academy Scientific Bulletin, Volume XX - 2017 - Issue 1 \\ The journal is indexed in: PROQUEST / DOAJ / Crossref / EBSCOhost / INDEX COPERNICUS / DRJI / OAJI I JOURNAL INDEX I I2OR / SCIENCE LIBRARY INDEX / Google Scholar / Academic Keys/ ROAD Open Access I Academic Resources / Scientific Indexing Services / SCIPIO / JIFACTOR}

The smoothness surface of drawing piece is influenced primarily by the smoothness surfaces blank. The smoothness of the surface part to be obtained is influenced by the smoothness of the surface of the drawing plate and the element pressing and retaining. Lubrication and quality of the lubricant used can influence surface smoothness part to be obtained. The presence of impurities, for example of hard oxides on the surfaces of the plate of drawing and pressing retaining element, that the wear of these surfaces, may worsen the surface smoothness of the part to be obtained. The coatings can improve the smoothness of the surface part to be obtained.

Physical continuity of the material part to be obtained is one of the main quality characteristics of these parts. Appearance of fissure, cracks and breakage in the material piece compromise quality, even if their precision and surface smoothness is good.cracks. These material discontinuities may be due to a number of important factors. Thus, the drawing forces greater than those which is capable to take over the wall of the workpiece from dragging of the blank into the die by the punch, can lead to such discontinuities. These forces too high may be due to a degree of drawing too great, a retaining presses higher than optimal or insufficient plasticity of the material blank. The radius too small of the drawing plate can give rise to large tension bending of material, that also contribute to increasing the drawing force. The sped deformation too high, as well as its variation during drawing, changes the behavior of the material blank as though would reduce the plasticity, becoming brittle and promoting the crack formation. Strong hardening of the material during cupping can determine the occurrence fissures in the material part to be obtained. The punch radius too small can give rise to stress and strain of bending too high, which can lead to pronounced thinning of the material piece, strong hardening and crack formation or even rupture to the workpiece material.

The metallographic structure of the workpiece material may influence the physical continuity featureFor example, fine grained material helps maintain a good physical continuity while coarseness favors crack formation. This can be explained by a fine dispersion of impurities from the edge of the crystalline grains and of these in the fine grain case and therefore an increase in the mechanical strength of the material.

The characteristics of the material drawing part primarily refers to the physical, chemical and mechanical characteristics such as: strength, hardness, elasticity, wear resistance, fatigue resistance, corrosion resistance, electrical and thermal conductivity. The nature of the material drawing part, ferrous or non-ferrous, chemical composition and metallographic structure influence these characteristics. A greater degree of drawing leads to hardening of the material and hence an increase in mechanical resistance characteristics, increasing the elasticity and decreasing the corrosion resistance and electrical conductivity. Strong cold plastic deformation leads to shredding the crystalline grains and increased mechanical strength of the workpiece material. To reduce the residual stresses of the material that negatively influence the workpiece precision over time, may be applied the stress-relieving treatment which removes the residual internal stresses and still retain high strength and hardness of material characteristics.

\section{Conclusions}

From the featured ones the above results the number of factors that influence the quality of drawing parts and particular complexity of the interactions between these factors with each other and with the quality of drawing parts. For this reason, for improving of processing technologies by drawing recourse to the modeling as close to reality using finite element method. 
"Mircea cel Batran" Naval Academy Scientific Bulletin, Volume XX - 2017 - Issue 1 The journal is indexed in: PROQUEST / DOAJ / Crossref / EBSCOhost / INDEX COPERNICUS / DRJI / OAJI I JOURNAL INDEX I I2OR / SCIENCE LIBRARY INDEX / Google Scholar / Academic Keys/ ROAD Open Access I Academic Resources / Scientific Indexing Services / SCIPIO I JIFACTOR

\section{Bibliography}

[1] Banabic D., Dorr I.T, Deformabilitateatablelormetalicesubtiri, Bucuresti, 1992

[2] Chioibas A. , The processing elements by drawing, SeaConf 2017, ANMB, Constanta

[3] Chioibas A. , Cercetariprivindinfluentaconditiilor de deformareasupracalitatiipieselorambutisate, Bucuresti, 2004

[4] http_www_nissin-prescision_com-image-Press2_jpg.htm, Samples of layouts of deep drawing progressive dies

[5] Iliescu C., Tehnologiapresarii la rece , EDP, Bucuresti, 1984

[6] Teodorescu M., ZguraGh., Tehnologiapresarii la rece, EDP, Bucuresti, 1980

[7] Teodorescu M.,sa, Prelucrariprindeformare plastic la rece, EdituraTehnica, Bucuresti, 1987

[8] Tureac I., Tabara V. , Masinipentruprelucrareaprindeformare, EDP, Bucuresti, 1979 